\title{
Market Completeness: How Options Affect Hedging and Investments in the Electricity Sector ${ }^{1}$
}

\author{
Bert Willems \\ TILEC and CenteR, Tilburg University, the Netherlands \\ b.r.r.willems@uvt.nl \\ Joris Morbee \\ Center for Economic Studies, KULeuven, Belgium \\ joris.morbee@econ.kuleuven.be
}

March 30, 2009

\begin{abstract}
The high volatility of electricity markets gives producers and retailers an incentive to hedge their exposure to electricity prices by buying and selling derivatives. This paper studies how welfare and investment incentives are affected when an increasing number of derivatives are introduced. It develops an equilibrium model of the electricity market with risk averse firms and a set of traded financial products, more specifically: a forward contract and an increasing number of options. We first show that aggregate welfare (the sum of individual firms' utility) increases with the number of derivatives offered, although most of the benefits are captured with one to three options. Secondly, power plant investments typically increase because additional derivatives enable better hedging of investments. However, the availability of derivatives sometimes leads to 'crowding-out' of physical investments because capital is being used more profitably to speculate on financial markets. Finally, we illustrate that players basing their investment decisions on risk-free probabilities inferred from market prices, may significantly overinvest when markets are not sufficiently complete.
\end{abstract}

\footnotetext{
${ }^{1}$ The authors would like to thank the participants of the workshop on "Policymaking Benefits and Limitations from Using Financial Methods and Modelling in Electricity Markets" in Oxford (July 2008) and of the seminar at Tilburg University for the insightful discussion. Special thanks to the discussant Thomas Tangerås, as well as to two anonymous reviewers. Furthermore, the authors would like to thank the three anonymous referees of Energy Economics, who provided helpful and constructive feedback. Joris Morbee gratefully acknowledges financial support from the KULeuven Energy Institute.
} 


\section{Introduction}

The specific characteristics of electrical energy create a need for hedging. Electricity cannot be stored economically, and therefore the price for electricity is determined by the supply and demand conditions at each given hour. As demand for electrical energy is very inelastic and of a stochastic nature and as generators face production capacity constraints, spot prices are very volatile. Liberalized electricity markets are therefore typically organized around regional spot markets for energy, which determine hourly spot prices, complemented with markets for long-term contracts, which help coordinate the actions of the players and allow for hedging of volume and price risks. The extent to which a firm can hedge its exposure, depends on the availability of markets, their liquidity (determined by such parameters as trading volume and bid-ask spread), and the presence of speculators who can absorb part of the risk. These factors change as markets evolve from pure OTC to sophisticated spot and futures markets, and to more complete markets in which there is a liquid trade of a broad set of derivatives. ${ }^{2}$

Recognizing that electricity markets are typically very incomplete, the objective of this paper is to analyze the effect of increasing market completeness on welfare and on investment incentives in the electricity sector. In our paper, market completeness is measured as the number of electricity options available to producers and retailers, in addition to a forward contract. Indeed, as more options with different strike prices become available, firms have more instruments to trade risks and markets become more complete. ${ }^{3}$ Welfare is defined as the sum of the utility of individual firms.

This paper develops an equilibrium model of the electricity market, which includes the production process, spot market trades and trade of derivatives. For illustrative purposes, the model is calibrated on the German electricity market, although an exact analysis of the German market is not the objective of this paper. First, the results show that adding option markets is welfare-enhancing, but that most of the benefits are obtained with one to three options. In particular, if firms have strong

\footnotetext{
${ }^{2}$ Note that vertical integration of electricity production and retail is an alternative way of creating a 'complete' set of hedging instruments between production and retail.

${ }^{3}$ The paper assumes that demand shocks are the only source of risk. In such a setting, the market is complete if options at every strike price can be traded. However, if there are also firm-specific shocks, then additional derivatives should be added for the market to be complete.
} 
aversion of negative shocks (shocks that would cause firm bankruptcy), then no equilibrium can be found unless option contracts are available in order to protect retailers against bankruptcy under all conditions. Second, we analyze how investment decisions by small firms are affected when an increasing number of derivatives are traded. We show that market incompleteness typically leads to underinvestment. The effects are, however, different for base load plants and peak load plants: the presence of forward contracts only (i.e., no options) is sufficient for investment in base load plants to reach the same level as in case of market completeness, but there will be underinvestment in peak load plants until there is a sufficient number of option contracts (which allow the investor to hedge market risk associated with the investment). Increasing the number of derivatives may, however, also lead to 'crowding-out' of certain investments in power plants, because the opportunity cost of financial capital increases: capital is being used more profitably to speculate on the newly created derivatives markets, instead of being invested in power plants. The amount of information contained in the equilibrium market prices, increases with the number of financial products being traded: it is shown that the quality of power plant investment decisions that are based on risk-free probabilities inferred from market prices, improves with the number of contracts being traded. If markets are not sufficiently complete, players basing their investment decisions on risk-free probabilities may significantly overinvest.

The model proposed in this paper is complementary to the traditional financial models for derivatives pricing, which are based on the no-arbitrage approach. In fact, it has been observed that it is difficult to apply the traditional no-arbitrage approach to the case of electricity derivatives, because the non-storability of electricity means that the well-known cost-of-carry relationship and delta-hedging strategy cannot be implemented, and hence pricing of electricity forwards and options cannot be done in the usual manner. ${ }^{4}$ For that reason, Bessembinder and Lemmon (2002) adopt an equilibrium approach and explicitly model the economic determinants of market clearing forward prices. Bessembinder and Lemmon's (2002) model was only focused on forward contracts, and in our paper we extend

\footnotetext{
${ }^{4}$ Eydeland and Geman (1998) present a pricing model for power options that relies on assumptions regarding the evolution of forward power prices. They show that the approach is adequate to manage monthly and yearly power options, but that it does not offer a safe solution for daily options.
} 
their model to include an increasing number of options in addition to a forward contract. We then use the model to study the effects of increasing market completeness on welfare and on investment incentives.

The paper is organized as follows. First, section 2 provides an overview of relevant research on incomplete markets, including the applicability to electricity markets. Next, section 3 describes the electricity market model that is used to obtain the results of this paper, while section 4 describes the model data. Section 5 verifies the welfare effects of an increasing number of markets. Sections 6 and 7 analyze the effect on investment incentives, based on welfare considerations (section 6) and on risk-free probabilities, i.e. the 'finance approach' (section 7). Finally, section 8 summarizes our conclusions.

\section{Literature review}

The topic of this paper is closely related to the literature on incomplete markets and financial innovation, as well as to the literature on hedging in electricity markets. In this section we first introduce the concept of incomplete markets. Next, we discuss the main results of the literature. Finally, we highlight the relevance for electricity markets and discuss related work on hedging in electricity markets. We base our discussion on market completeness mainly on Staum (2008) and Duffie and Rahi (1995).

\subsection{Incomplete markets}

Markets are incomplete when perfect risk transfer between the agents is impossible. There might be several reasons why this would be the case. First, the marketed set of assets may be insufficient to hedge the class of risk one wishes to hedge. This type of incompleteness deals with the spanning role of securities (see also Allen and Gale, 1994). Second, markets might be imperfect due to the existence of transaction costs and/or trading constraints. For instance, firms might not be able to take a short position in a traded security. These costs and/or constraints make it effectively impossible to transfer risk perfectly. In our paper we focus on the first type of market incompleteness: the missing markets problem. 
In practice, markets are never complete, as not all risk factors are traded on a market. Hence, when might market incompleteness be relevant for hedging or pricing decisions? We mention two situations in which this might be the case. The first situation is when some of the variables one would like to hedge are derived from non-market prices, as is the case for weather derivatives. The second typical situation of market incompleteness occurs when the price of an asset does not follow a standard random walk process - where prices changes are 'infinitesimally small' but contains 'large' price jumps. The problem with price jumps is that a hedging strategy which dynamically adjusts a portfolio containing the underlying asset and a risk-free bond, is no longer possible, as the payout is non-linear in the size of the shock. In order to complete the market one would need to add a forward market and a set of option markets with different strike prices.

\subsection{Research results on incompleteness}

The first main result of the literature on welfare effects and pricing of additional assets is that welfare in an incomplete market is lower than in a complete market because not all risk is perfectly allocated in the market. ${ }^{5}$ This is a rather intuitive result: as in an incomplete market not all potential gains from trade are exhausted, total welfare can be improved by a sufficient number of additional markets until the market is complete. This simple intuition does, however, not carry over to situations where only one additional market is added to the economy, without completing the market. Hart (1975) shows that adding a financial product might make every one in the economy worse off. Extending this result, Elul (1995) and Cass and Citanna (1998) show that in an economy with many consumption goods one can always find an asset that makes everyone worse off, or an asset that makes everyone better off,

\footnotetext{
${ }^{5}$ In this paper we assume that a Walrasian equilibrium exists, even when markets are incomplete. In a general equilibrium setting with multiple goods, (where securities can contain different bundles of goods), this is not guaranteed. However, when we restrict ourselves to economies where financial claims only have a pay-off in terms of a single numeraire good, existence is guaranteed. On existence of equilibria in a general equilibrium setting, see Duffie and Shafer (1985) and Duffie and Shafer (1986).
} 
or an asset that makes any combination of individuals better or worse off. ${ }^{6}$ Note that introducing all financial assets (completing the market) does not necessarily make everyone better off. Complete markets are Pareto efficient, but not necessarily Pareto dominant with all possible incomplete market allocations. Willen (2005) studies the impact of market innovation in more detail and shows that, when agents have exponential utility and risk is normally distributed, the effect of a financial innovation can be split up in a portfolio effect and a price effect. Elul (1999) studies the welfare effects of a financial innovation in a single-good market.

Boyle and Wang (2001) study the pricing of a new derivative in an incomplete market. They show that one should not use the standard arbitrage assumptions typically used in the financial (engineering) literature, as the prices of existing assets may change once a new asset is added to the economy. ${ }^{7}$ Instead, they recommend to make explicit assumptions on the preferences of the agents in the economy and to use an equilibrium model to derive the prices of the different assets. Staum (2008) and Carr et al. (2001) argue however that results of equilibrium models depend very much on the choice of the utility function, the initial endowment of the firms, and the parameters of the probability measure, and are therefore not useful for trading decisions.

\subsection{Incompleteness and hedging in electricity markets}

The electricity market is an interesting example of a very incomplete market. Since electricity cannot be stored economically and electricity prices are very volatile, it is difficult to hedge even the most basic forward contracts and plain vanilla options, when they are not traded directly in the market. Our paper focuses on the electricity market and builds further upon existing studies on contracting and hedging in this market. ${ }^{8}$

\footnotetext{
${ }^{6}$ Similar results were obtained earlier by Milne and Shefrin (1987) in a specific model set-up. Note that the results are not applicable here because our model assumes only one relevant good: money.

${ }^{7}$ They also show that the condition of arbitrage-free pricing does not determine a unique price for the newly created asset.

${ }^{8}$ In the review we limit ourselves - with the exception of Oum et al. (2007) - to studies that rely on equilibrium models of the electricity market. The alternative to equilibrium models is the study of
} 
First of all, Bessembinder and Lemmon (2002) develop a partial equilibrium model of the spot market and one forward market. They derive analytical solutions for forward and spot prices in a setting in which firms are risk averse, production cost are convex, retail prices are fixed and demand is stochastic. Their theoretical predictions on risk premia are verified empirically: the model correctly predicts when markets should be in backwardation or in contango. Siddiqui (2003) completes the Bessembinder and Lemmon (2002) model by introducing a forward market for ancillary services (reserve capacity) and deriving analytical results that link the forward prices of electricity and ancillary services with the statistical properties of the spot price. Our paper also extends the framework of Bessembinder and Lemmon (2002) and allows for multiple financial products to be traded - not just one forward contract. ${ }^{9}$ Furthermore, our paper analyzes the effects of speculators trading in a number of derivatives markets and studies an alternative, more realistic formulation of risk aversion. In addition, the effect on investments is analyzed.

The usefulness of financial instruments other than forwards to hedge risks in electricity markets is discussed by Oum et al. (2007). They show that a regulated retail firm can use a combination of forwards, call options and put options to hedge its volumetric risk, and draw attention to the regulated firm's difficulty to hedge when regulators forbid trade in derivatives that look speculative, such as weather derivatives, and rebuff contracting positions that require the firm to pay a sum exante. The optimal hedging strategy is found by optimizing the firm's utility, subjective to the financing constraint. The results are derived for the CARA and the mean-variance utility functions, with an endogenously given price and quantity distribution function. In our paper we develop an equilibrium model of the market and show that option contracts are important instrument to transfer volumetric risks from generators to retailers, even more so when firms might face liquidity constraints (which we model through a CRRA utility function, see below). We also show the importance of options for investment decisions.

one firm's contracting and production decisions for an exogenously given stochastic spot price process and forward price.

${ }^{9}$ With a forward contract this paper refers to a contract for future delivery of a fixed quantity of a good at a fixed price. We will not explicitly specify whether these contracts are traded over the counter (OTC), or whether they are traded as 'futures' on a centralized power exchange. 
Baldursson and von der Fehr (2007) study vertical integration, forward contracting and hedging in an equilibrium electricity market model. They show that vertical integration might increase the equilibrium risk premia in the market and lower overall welfare, compared with forward contracting. The reason why this happens in their model is that they assume that a vertically integrated firm has a 'smaller capacity' to take up risk than two separate entities combined. Even though our model does not represent vertical integration explicitly, the case of vertical integration in our model corresponds to the case in which perfect risk-transfer between producer and retailer is possible, i.e., the case of market completeness. In such a setting, the implicit assumption is that the vertically integrated firm has the 'same capacity' to take up risk as the two separate firms combined. In our opinion, this is a more realistic assumption. We see the difference between vertical integration and contracting by means of a forward contract, as follows: within the vertically integrated firm, risk sharing between generation and retail is perfect, while risk sharing by trading forward contracts is imperfect, leaving part of the risk untraded..$^{10}$

Also Aid et al. (2006) study vertical integration, forward contracting, hedging, and retail competition. They develop an equilibrium model in which firms have a meanvariance utility function and show that both vertical integration and forward contracting allows for a better risk sharing between retailers and generators and leads to lower retail prices, increased market share for small generators, and a reduction of the profits of retailers. Compared with long-term contracts, vertical integration leads to perfect risk sharing between generators and retailers. Additionally, forward markets might not develop under some parameters of the game in which case no risk is shared between upstream and downstream firms. The results of Aid et al. (2006) on the comparison of vertical integration and forward contracting are driven by the change of the utility function (and the implied capacity of firms to take up risks) and the quality of risk transfer between upstream and downstream firms (market completeness). In our paper we single out the effect of market completeness. We do not, however, study retail competition. Our paper

\footnotetext{
${ }^{10}$ An additional difference between vertical integration and trading derivatives is that in a derivatives market, financial investors can reduce the risk premia in the market.
} 
assumes a perfectly competitive market and neglects strategic issues associated with long-term contracting that have been reported in the literature.

Allaz and Vila (1993) study the role of forward contracts, not as a tool to hedge risks, but as an instrument used by oligopolists to strategically affect market outcomes. It is shown that in a Cournot setting, generation firms sell forward contracts in order to commit to compete more aggressively in the spot market. Hence forward contracts make markets more competitive. Willems (2006) shows that a similar mechanism is at work with financial call options: the market equilibrium is even more competitive than with future contracts.

Green (2003) studies the combined hedging and strategic roles of forward contracts while at the same time examining different types of competition in the retail market. He shows that retail competition may lower the amount of forward contracts firms will sign. The current paper does not allow for retail competition, - consumers cannot switch retail supplier - and assumes, as in Bessembinder and Lemmon (2002), that retail prices are fixed.

Green (2007) models investment decisions and the technology choice in a long-term oligopolistic equilibrium model with risk averse firms in which firms can sign forward contracts. The setting of our paper allows us to analyze the relation between market completeness and investment decisions of generators.

\section{Model description}

We extend the competitive market equilibrium model of the forward and spot markets developed by Bessembinder and Lemmon (2002). The main difference with their model is that we allow for multiple financial products to be traded on the market. We start with a description of the spot market and continue with a description of the derivatives markets.

We consider an electricity sector with $N_{g}$ identical generation firms and $N_{r}$ identical retailers. Demand for electricity $D$ is inelastic and stochastic. The total production cost of the industry is the sum of a fixed cost $F$ and a variable cost:

$$
C(Q)=F+\frac{a}{c} Q^{c}
$$

where $F, a$ and $c$ are parameters that determine the shape of the cost function. 
The spot market is perfectly competitive, and the wholesale price for electricity $P$ is determined by market clearing:

$$
P=C^{\prime}(D)=a D^{c-1}
$$

As demand is a random variable, so is the spot price.

The combined profit of the generators is equal to spot market revenue minus production costs:

$$
\pi_{g}=P \cdot D-C(D)
$$

Retailers buy energy on the spot market and sell it at a fixed retail rate $R$ to consumers. ${ }^{11}$ The combined profit of the retailers is equal to:

$$
\pi_{r}=(R-P) D
$$

Both retailers' and generators' profits are affected by the stochastic nature of demand.

In the derivatives market, a derivative $i \in\{1, . ., I\}$ is traded at a price $F_{i}$. The derivative promises a payment $T_{i}(P)$, which is conditional on the spot price $P$. This paper assumes that the only derivatives which are traded are call options. Hence:

$$
T_{i}(P)=\max \left(P-S_{i}, 0\right)
$$

with $S_{i}$ the strike price of option $i$. A derivative with strike price zero corresponds to the standard forward contract.

The combined profit $\Pi_{j}(j=r, g)$ that is made by retailers and generators, respectively, when the retailers/generators buy a total of $k_{i}^{j}$ derivatives in the derivatives market, is equal to:

$$
\Pi_{j}=\pi_{j}(P)+\sum_{i=1}^{I} k_{i}^{j} \cdot\left(T_{i}(P)-F_{i}\right)
$$

The firms' profit is the sum of the profit they make in the spot market, and the profit they make on the derivatives they have bought. Both terms are stochastic as they depend on the realization of the demand level.

We assume that retailers and generators are risk averse, and that the utility of individual retailers and generators can be described by a mean-variance utility

\footnotetext{
11 The fixed rate $R$ is either a regulated rate, or a fixed price contract offered to customers in a deregulated market. The case of real-time pricing, which would allow retailers to transfer upward price risk to the consumers, is discussed in section 5 .
} 
function with risk aversion parameter $N_{j} A(j=r, g)$. The risk aversion parameter contains $N_{j}$ to account for the fact that a larger number of firms would lead to a smaller average size per firm, and therefore a proportionally smaller risk-bearing capacity, i.e. a higher absolute risk aversion. When $N_{g}=N_{r}$, the risk aversion of all firms (both generators and retailers) is the same, a reasonable assumption. If $U_{j}$ $(j=r, g)$ represents the combined utility of all retailers and generators, respectively, then each identical individual firm will maximize its utility $U_{j} / N_{j}$ :

$$
\frac{U_{j}}{N_{j}}=\mathrm{E}\left(\frac{\Pi_{j}}{N_{j}}\right)-\frac{N_{j} A}{2} \operatorname{Var}\left(\frac{\Pi_{j}}{N_{j}}\right) \quad j=r, g
$$

Maximizing (7) is equivalent to maximizing the following:

$$
U_{j}=\mathrm{E}\left(\Pi_{j}\right)-\frac{A}{2} \operatorname{Var}\left(\Pi_{j}\right) \quad j=r, g
$$

which has the intuitively appealing benefit of not containing $N_{j}$ anymore. One could say that the risk aversion parameter $A$ measures the risk aversion of either the generation sector or the retail sector as a whole. We can proceed with the analysis as if there was only one generator and one retailer. Aggregate market welfare $W$ is equal to the sum of the utility of retailers and generators: $W=U_{r}+U_{g}$.

In the contracting stage, firm $j$ maximizes its utility $U_{j}$, by choosing the amount of derivatives $k_{1}^{j}, \ldots, k_{i}^{j}, \ldots, k_{I}^{j}$ it buys or sells. The equilibrium contract positions are given by:

$$
\vec{k}^{j}=\Sigma^{-1} \frac{\mathrm{E}(\vec{T})-\vec{F}}{A}-\Sigma^{-1} \operatorname{Cov}\left\{\pi_{j}, \vec{T}\right\}
$$

with $\vec{k}^{j}=\left(k_{1}^{j}, \ldots, k_{I}^{j}\right)$, the vector of equilibrium quantities bought by player $j$, $\Sigma=\operatorname{Cov}\{\vec{T}, \vec{T}\}$ the $I$ by $I$ covariance matrix of the contracts $\vec{T}=\left(T_{1}, \ldots, T_{I}\right)$, $\vec{F}=\left(F_{1}, \ldots, F_{I}\right)$ the derivative price vector, and $\operatorname{Cov}\left\{\pi_{j}, \vec{T}\right\}$ the 1 by $I$ covariance matrix of contracts and firm $j$ 's profit.

Equation (9) shows that the amount of contracts firm $j$ buys is the sum of two terms. The first term is the pure speculative amount of contracts a firm would like to buy. If a financial derivative has an expected positive return, then the firm will buy some of it, as long as it does not increase the variance of its portfolio too much. The 
second term is the pure hedging demand by the firm. A firm $j$ will buy derivatives in order to hedge its profit risk. It will buy more of a certain derivative, if it is more correlated with the profit it wants to hedge, and if the impact on the variance of the portfolio is smaller.

In equilibrium the demand and supply of derivative products should be equal. Hence, if there are no speculators active in market $i$ we find:

$$
k_{i}^{r}+k_{i}^{g}=0
$$

and using equation (9) the equilibrium price of derivative $i$ is given by:

$$
F_{i}=\mathrm{E}\left(T_{i}\right)-\frac{A}{2} \operatorname{Cov}\left\{\pi_{g}+\pi_{r}, T_{i}\right\}
$$

Hence, the price of a derivative is equal to the expected pay-off of the derivative minus a term which reflects the fact that the derivative is used to hedge the risk of the individual firms. The last term depends on the risk aversion of all the firms and the covariance of industry profit with financial instrument $i$. It is worth noting that the price of the derivative does not depend on the number of products traded in the market. $^{12}$

If risk neutral speculators are active in derivatives market $i$, then the risk premium becomes zero, and the price of the derivative should be equal to its expected value:

$$
F_{i}=\mathrm{E}\left(T_{i}\right)
$$

\section{Model data}

The model is calibrated on the German electricity market, using technical and market data recorded in the first two months of 2006. Note that the purpose of the calibration is to allow us to perform simulations that produce intuitively relevant results. The numbers thereby serve as an illustration - this paper does not claim to make exact statements about the impact of option trade on the German electricity sector.

The marginal production cost curve $C^{\prime}(Q)$ is calibrated on the actual German marginal production cost curve, as explained in Appendix A. Demand is assumed to be normally distributed with mean $60 \mathrm{GW}$ (which is the average of the observed

\footnotetext{
${ }^{12}$ In standard mean-variance settings, risk pricing is not affected. Specifically, in quadratic or CARAnormal economies, the price of any risky security relative to the bond is unaffected by changes in the span. See Oh (1996).
} 
sample) and standard deviation $17 \mathrm{GW}$. The standard deviation is chosen in such a way that the standard deviation of the resulting power price (according to equation (2)) corresponds to the standard deviation of the sample of observed prices. Given the assumptions about supply and demand, we can derive the wholesale price distribution. The distribution has a mean of $48 \mathrm{EUR} / \mathrm{MWh}$ and a standard deviation of 35 EUR/MWh. Bessembinder and Lemmon (2002) show that as the industry marginal cost function is convex, the price distribution is skewed.

Retailers and generators have the same risk aversion parameter $A=0.0025$, which has the unit (h/1000 EUR). Furthermore, we assume that the fixed cost parameter $F=1200$ (expressed in $1000 \mathrm{EUR} / \mathrm{h})$, and that retailers sell their energy at a fixed price of 58 EUR/MWh. Note that prices and quantities are expressed in (EUR/MWh) and (GW), respectively, and hence profits and total costs are expressed in $(1000 \mathrm{EUR} / \mathrm{h})$.

\section{Welfare effects}

In this section, we use the model to calculate the optimal hedging strategy of generators and retailers, and analyze the welfare effects of adding additional derivatives to the market. In the first part of the simulations we assume that no speculators are active on the market, and hence supply and demand of financial contracts is only from retailers and generators. We consider four scenarios with a different number of derivative markets present. In Scenario 1, only a forward market exists. In Scenarios 2 through 4, the forward market is supplemented with one, three, and eleven additional option markets, respectively. ${ }^{13}$

Table 1 shows the simulation results for all scenarios. It shows for each of the twelve derivative contracts the net amount traded by generators and retailers. Positive numbers represent long positions, negative numbers represent short positions. The option contracts have strike prices ranging from 0 to 143 EUR / MWh, with the zero strike price (contract 1) corresponding to the forward contract. The range of option strike prices covers the $95 \%$ confidence interval of price levels.

\footnotetext{
13 The numerical model is written as a Mixed Complementarity Problem (MCP) in GAMS. See Appendix B.
} 


\begin{tabular}{|c|c|c|c|c|c|c|c|c|c|c|}
\hline & & & \multicolumn{8}{|c|}{ Net Contract Position } \\
\hline & & & \multicolumn{2}{|c|}{$\begin{array}{c}\text { Scenario } 1 \\
\text { Forward } \\
\end{array}$} & \multicolumn{2}{|c|}{$\begin{array}{c}\text { Scenario } 2 \\
\text { Forward }+1 \text { Option } \\
\end{array}$} & \multicolumn{2}{|c|}{$\begin{array}{c}\text { Scenario } 3 \\
\text { Forward }+3 \text { Options } \\
\end{array}$} & \multicolumn{2}{|c|}{$\begin{array}{c}\text { Scenario } 4 \\
\text { All Contracts } \\
\end{array}$} \\
\hline (i) & $S_{i}$ & $F_{i}$ & $k_{i}^{g}$ & $k_{i}^{r}$ & $k_{i}^{g}$ & $k_{i}^{r}$ & $k_{i}^{g}$ & $k_{i}^{r}$ & $k_{i}^{g}$ & $k_{i}^{r}$ \\
\hline 1 & 0 & 45.3 & -68.0 & 68.0 & -52.0 & 52.0 & -32.1 & 32.1 & 5.3 & -5.3 \\
\hline 2 & 13 & 33.6 & & & & & & & -37.9 & 37.9 \\
\hline 3 & 26 & 25.2 & & & & & & & -16.2 & 16.2 \\
\hline 4 & 39 & 19.1 & & & & & -37.7 & 37.7 & -11.1 & 11.1 \\
\hline 5 & 52 & 14.5 & & & & & & & -8.3 & 8.3 \\
\hline 6 & 65 & 10.9 & & & & & & & -6.9 & 6.9 \\
\hline 7 & 78 & 7.9 & & & -45.4 & 45.4 & -15.9 & 15.9 & -5.9 & 5.9 \\
\hline 8 & 91 & 5.6 & & & & & & & -5.2 & 5.2 \\
\hline 9 & 104 & 3.8 & & & & & & & -4.3 & 4.3 \\
\hline 10 & 117 & 2.4 & & & & & -14.5 & 14.5 & -6.6 & 6.6 \\
\hline 11 & 130 & 1.3 & & & & & & & 3.7 & -3.7 \\
\hline 12 & 143 & 0.7 & & & & & & & -13.1 & 13.1 \\
\hline & Welfare & $W$ & 768 & & & & & & 133 & \\
\hline
\end{tabular}

Table 1: Market equilibrium without speculation

The results show that if there are only forward contracts, firms overhedge their positions. Generators sell $68 \mathrm{GW}$ forward, while in expected terms they will only produce $60 \mathrm{GW}$. The intuitive explanation for this is that generators and retailers want to hedge volumetric risk (or quantity risk), in addition to price risk. If there were only price risk (i.e., the quantity of electricity demanded would be deterministic), then forward contracts - which are specifically suited for hedging price risk - would be sufficient. The number of forward contracts would exactly correspond to the deterministic demand quantity. However, in the setting of this paper (and in reality), generators and retailers are exposed to both volumetric risk and price risk, because both quantities and prices are stochastic. If no options are traded, then volumetric risk can be hedged using additional forwards, because price and quantity are positively related. Another way of explaining this effect is that, because price and quantity are positively related, overall risk exposure is convex in the underlying state variable (demand) and hence the number of forward contracts exceeds expected demand. The price of the forward contract is $45.3 \mathrm{EUR} / \mathrm{MWh}$, which is below the expected spot price of $48 \mathrm{EUR} / \mathrm{MWh}$.

In Scenarios 2 to 4, extra financial instruments are added to the market. Table 1 shows that once more instruments become available, generators reduce the amount of standard forward contracts they sell and substitute these contracts with option contracts. The generators and the retailers reduce their supply and demand of forward contracts. Although both demand and supply functions shift, the price of the forward contract remains $45.3 \mathrm{EUR} / \mathrm{MWh}$ as shown in derivation (11). As we 
pointed out in footnote 12 , this effect is due to the use of the mean-variance utility function.

The last row in Table 1 is the aggregate welfare, measured in certainty equivalents (1000 EUR/h). Increasing the number of contracts traded clearly increases market efficiency. The introduction of one option contract, when none existed before, increases welfare by approximately $50 \%$. Adding extra markets for option contracts increases welfare further, but to a lesser extent. For instance, increasing the number of option markets from 3 to 11 , increases welfare by $1.2 \%$. Hence risk sharing between generation and retail is close to optimal once one option contract (or a few option contracts) are traded. In fact, the welfare effects in Scenario 2 (Forward +1 Option) can be improved even further, by modifying the strike price of the one available option contract. The strike prices of the option contracts in the simulations of Table 1 are chosen so that they span the $95 \%$ confidence interval of price levels. Scenario 2 assumes that one option is available, with a strike price roughly in the middle of this price range. Figure 1 shows how welfare would change when a different strike price is used.

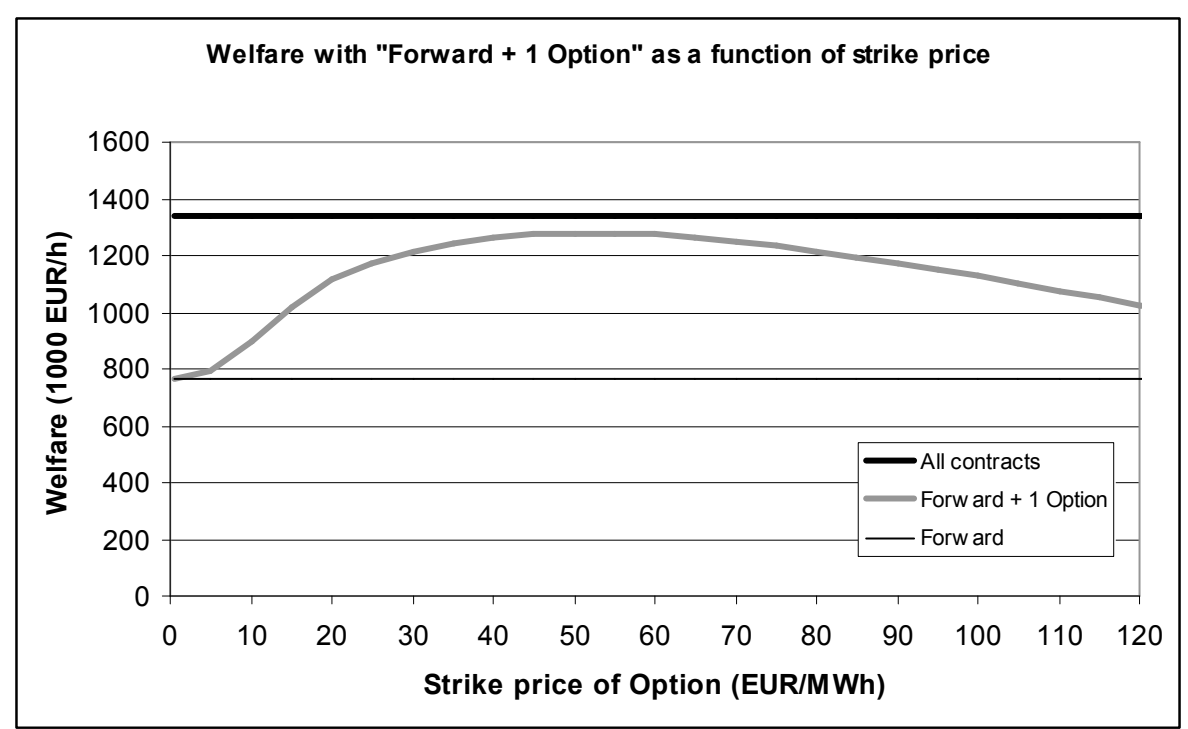

Figure 1: Welfare obtained with "Forward + 1 Option", for different strike prices (compared with welfare obtained with only a "Forward" and with "All contracts")

If the strike price of the option is very low, then welfare is equal to welfare obtained with a forward contract only, because the option does not add any new hedging possibilities. Welfare reaches a plateau optimum of 1280 (expressed in $1000 \mathrm{EUR} / \mathrm{h}$ ) 
when the strike price is in the 50-55 EUR/MWh range. However, for all strike prices in the 30-80 EUR/MWh range, adding the one option contract to the forward contract lifts welfare above 1200 (in $1000 \mathrm{EUR} / \mathrm{h}$ ), thereby capturing more than $75 \%$ of the potential benefits of market completeness.

Until now, we have assumed that retailers sell at a fixed price $R$, which can be either a regulated rate, or a fixed price contract offered to customers in a deregulated market. Given the continuous development of more sophisticated metering systems, it is interesting to consider what would happen if real-time pricing were possible. If all consumer contracts were based on real-time prices, then this would eliminate all risk for the retailers. However, generators would still have a desire to hedge. Smart retailers could therefore develop structured consumer contracts that take away risks from the generators and transfer them to the consumers who are willing to take on the risks. Such consumers would be rewarded with a lower expected power price. In its simplest form, such a structured contract could be similar to a fixed price contract. If options are available on the wholesale market (in addition to forwards) then more sophisticated structures would be possible, thereby hedging the generators' risk better and better, and improving welfare. In practice, in order to preserve the demand incentives created by real-time pricing, such structured contracts are still likely to price a consumer's individual demand based on real-time prices. However, at the end of each period, consumers could expect a check that settles the structured part of the consumer contract, i.e. the hedge, with the amount of the check depending on the overall demand and price developments in the spot market in the course of the period. ${ }^{14}$

For the second part of the simulations, we assume that speculators can actively participate in the market, by taking positions in the electricity derivative markets and financially closing their position in the spot market. We assume they trade away the risk premia in the market: the price of the derivatives becomes equal to the expected value of the derivative. As speculators provide extra liquidity to the market, the supply of derivatives by generators does no longer need to exactly balance the

\footnotetext{
14 Borenstein (2007) discusses retail markets and hedging in more detail. He shows how retail contracts can be developed that base the marginal price of electricity consumption on the real time price, but at the same time include a hedge which reduces monthly bill volatility.
} 
demand by retailers. The difference of generators' supply and retailers' demand is the position speculators take in the market. For the same four scenarios as before, Table 2 gives the net position of generators and retailers. In Scenario 1, only forward contracts exist, and generators sell $69.1 \mathrm{GW}$ forward, retailers buy $67 \mathrm{GW}$, and speculators buy $2.1 \mathrm{GW}$. The results indicate that the more derivatives markets are introduced, the larger the gap between supply and demand for forward contracts, and the larger the role played by speculators. In Scenario 4, in which there is one forward market and eleven option markets, generators sell $34.2 \mathrm{GW}$, retailers sell 44.8 GW and speculators buy $79 \mathrm{GW}$.

The introduction of speculators increases welfare, as the players can share their risk with players outside the market, the speculators. Hence, the addition of speculators does not change our previous conclusions. Speculators play an active role in the electricity market by taking up market risk and by decreasing the risk premia in the market. As the number of markets increases, the amount of risk that speculators take away from market participants increases, but the positive welfare effect of additional markets levels off after a few products.

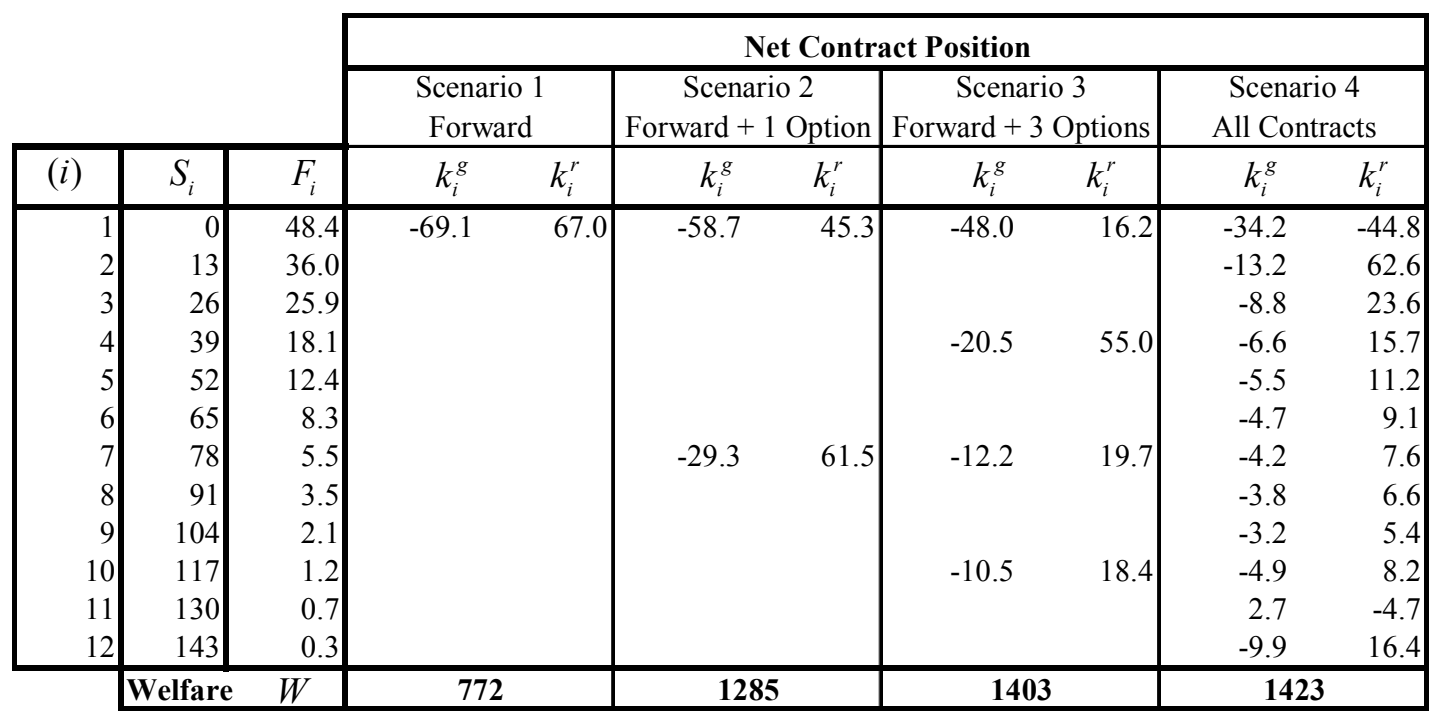

Table 2: Market equilibrium with speculation

Finally, for the third part of the simulations, we repeat the previous simulation but we now use a different assumption for firms' utility functions: instead of the utility functions from equation (7), we use the well-known CRRA utility function (i.e., the utility function with constant relative risk aversion). As a result of the CRRA property, firms become very averse of potential shocks that would lead to very low 
or negative profits. In other words, the CRRA utility function models a world in which firms want to avoid the risk of liquidity problems or bankruptcy. Practically, we choose the coefficient of relative risk aversion to be 4 , which is in the middle of the typical 2-6 range (see e.g. Palsson, 1996). The simulation results with speculation and CRRA utility functions for producers and retailers are shown in Table 3. Generally speaking, the results are very similar to the results of Table 2, although the retailer seems to have a slightly increased preference for options over forwards (as compared to Table 2).

The most interesting observation is that with the CRRA utility function, it is not possible to find a sufficiently hedged solution in the case when only forwards are present. In other words, if no options are introduced, welfare remains 'infinitely low' for CRRA utility functions. The reason is that forwards alone do not allow the retailer and the generator to limit their exposure in all 'states-of-the-world'. The intuition for this effect is the following: since a negative result in one potential stateof-the-world is strongly penalized by the CRRA function, the retailer and the generator would like to avoid - at all costs - any outcomes in which their profit is below a certain threshold, in order to avoid bankruptcy. The retailer faces a negative shock when demand is high (it faces a high wholesale price, and has to buy a large volume of power), and when demand is low (sales volume is too low to cover fixed costs). The generator faces a negative shock when demand is very low (low price and low volume). As the retailer wants to avoid bankruptcy at all cost, its demand for forward contracts is undetermined for any price of forward contracts. With only the forward contract, the retailer is unable to hedge against both the risk of having high demand and the risk of having low demand. Based on these results for a CRRA utility function, it is clear that the introduction of options is especially welfareenhancing if there is a strong risk aversion for negative shocks that could lead to bankruptcy.

A practical implication of this phenomenon would be that a retailer alone would have difficulty to survive if no liquid option market is available. Anecdotical evidence of this effect is the case of Centrica in the UK. After the demerger of British Gas (Centrica, 12/2/1997), Centrica was essentially a gas retailer in the UK. At the end of 1997, Centrica entered the electricity market as a pure retailer (without any generation assets) and acquired its first electricity customers (Centrica, 1/12/1997). Rather than staying a stand-alone gas and electricity retailer, Centrica 
started to invest in gas-fired power generation in 2001 (Centrica, 29/5/2001 and 24/8/2001). Centrica stated the following reason for the investments in power generation: "As part of its risk management strategy the company has said it plans to source 20-25 per cent of its future peak electricity requirements from its own generating capacity. This strategy offers increased long term stability and protection against electricity price fluctuations and spikes" (Centrica, 24/8/2001). In other words: the investment in gas-fired power generation is meant primarily to protect the retailer against electricity price volatility in case of peak demand. From a financial perspective, an investment in gas-fired power generation (which has relatively low investment cost and relatively high marginal cost) can be considered as the purchase of a call option on electricity, with a relatively high strike price ${ }^{15}$. The absence of a market for such options forces retailers to invest in the physical equivalent, because staying unhedged is not a viable alternative.

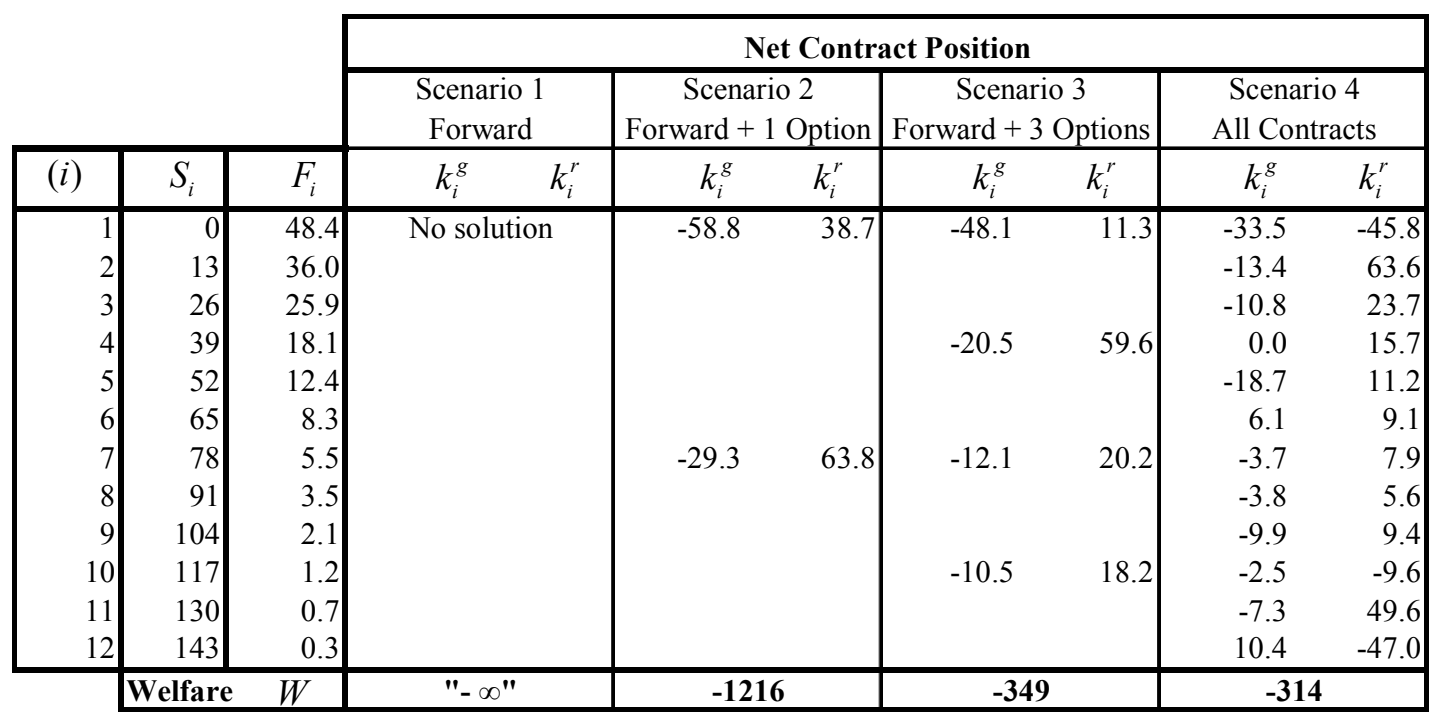

Table 3: Market equilibrium with speculation, with CRRA utility functions

\section{Investment decisions by small firms}

Above we have shown that the welfare effect of adding contracts levels off after a relatively small number of contracts. However, implicitly we have assumed that all production firms have a diversified portfolio of generation plants. Indeed: we

\footnotetext{
${ }^{15}$ Strictly speaking, a gas-fired power plant is an option on a (clean) spark spread, i.e., the difference between the electricity price and the input prices (gas, carbon emission rights).
} 
assume that there are $N_{g}$ identical production firms, which implies that the production cost curve of each firm is just a horizontally scaled version of the aggregate production cost curve of the generation industry. In other words, the portfolio of each firm contains power plants with relatively low marginal costs (e.g., nuclear power plants), which will be run in nearly all demand scenarios, and power plants with relatively high marginal costs (e.g., gas-fired power plants), which will be run only if demand is high. As a result, all generation firms are reasonably diversified, and the demand/price risk is adequately distributed across generation firms. However, if some firms have only base load power plants and other firms have only peak load power plants, then some firms' financial results are much more sensitive to certain demand/price scenarios. Intuitively, this could make the potential social value of a comprehensive set of financial contracts (which would allow risktransfer under accurately defined demand/price scenarios) significantly higher.

In order to test the impact of market completeness when firms have different types of portfolios, we analyze how risk trading modifies investment behavior. Specifically, we determine whether a small, non-diversified firm would invest in a single power plant with marginal cost $c$ and fixed investment cost $F{ }^{16}$ The small firm is assumed to be risk averse, with mean-variance utility function (as in the first part of our simulations). We assume no speculators in the market.

The firm invests in this production plant if the investment increases its expected utility. The expected utility without investments is equal to

$$
\begin{aligned}
& U^{N I}=\max _{k_{1}, \ldots, k_{I}}\left[\mathrm{E}\{\pi\}-\frac{A}{2} \operatorname{Var}\{\pi\}\right] \\
& \text { with } \quad \pi=\sum_{i=1}^{I} k_{i} \cdot\left(T_{i}(P)-F_{i}\right)
\end{aligned}
$$

while the expected utility with investments is equal to

$$
\begin{aligned}
& U^{I N V}(c, F)=\max _{k_{1}, \ldots, k_{I}}\left[\mathrm{E}\{\pi\}-\frac{A}{2} \operatorname{Var}\{\pi\}\right] \\
& \text { with } \quad \pi=\sum_{i=1}^{I} k_{i} \cdot\left(T_{i}(P)-F_{i}\right)+(\max \{p-c, 0\}-F)
\end{aligned}
$$

The firm invests as long as

\footnotetext{
${ }^{16}$ Since such a power plant is in fact (almost) equivalent to an option contract, this essentially means that we analyze the implications of providing one player with one additional contract.
} 


$$
U^{N I}>U^{I N V}(c, F)
$$

Equation (15) defines implicitly the maximum fixed cost for which the firm is willing to invest in new generation capacity with marginal cost $c$. Hence investment occurs as long as

$$
F<F^{c r}(c)
$$

Therefore, the function $F^{c r}(c)$ represents the investment behavior of the firm. ${ }^{17}$ $F^{c r}(c)$ obviously depends on the number and types of financial contracts traded in the market, and on the risk aversion of the firm. Indeed, generally speaking, as more contracts are traded, the firm is able to better hedge the output of the production plant, thereby reducing its risks. This makes it more interesting for the firm to build a power plant. In certain cases, there is, however, a non-monotonic relation between market completeness and investments decisions, as will see below. Let $\bar{F}^{c r}(c)$ denote the case of market completeness, i.e., the firm's investment behavior if a full set of option contracts is available.

Figure 2 compares the decision behavior of risk averse firms in case of market incompleteness with the decision behavior in case of market completeness. More specifically, the figure shows the "adjustment factor" $\kappa$ :

$$
\kappa=\frac{F^{c r}(c)}{\bar{F}^{c r}(c)}
$$

When calculated for different levels of market completeness, the factor $\kappa$ describes how the firm's investment decisions change as markets become more complete. Those investments decisions are the profit-maximizing decisions for the firm (conditional on the available contracts). Note that the firm's risk aversion is chosen at a higher level than before, because we analyze a small firm and the mean-variance utility function does not scale.

If $\kappa<1$, the firm invests less in a particular type of generation than if markets were complete. If $\kappa>1$, the firm invests more in a particular type of generation than if markets were complete.

\footnotetext{
${ }^{17}$ If we consider the power plant as an option contract, then $F^{c r}(c)$ is the maximum price (option premium) the firm would be willing to pay for this option contract.
} 


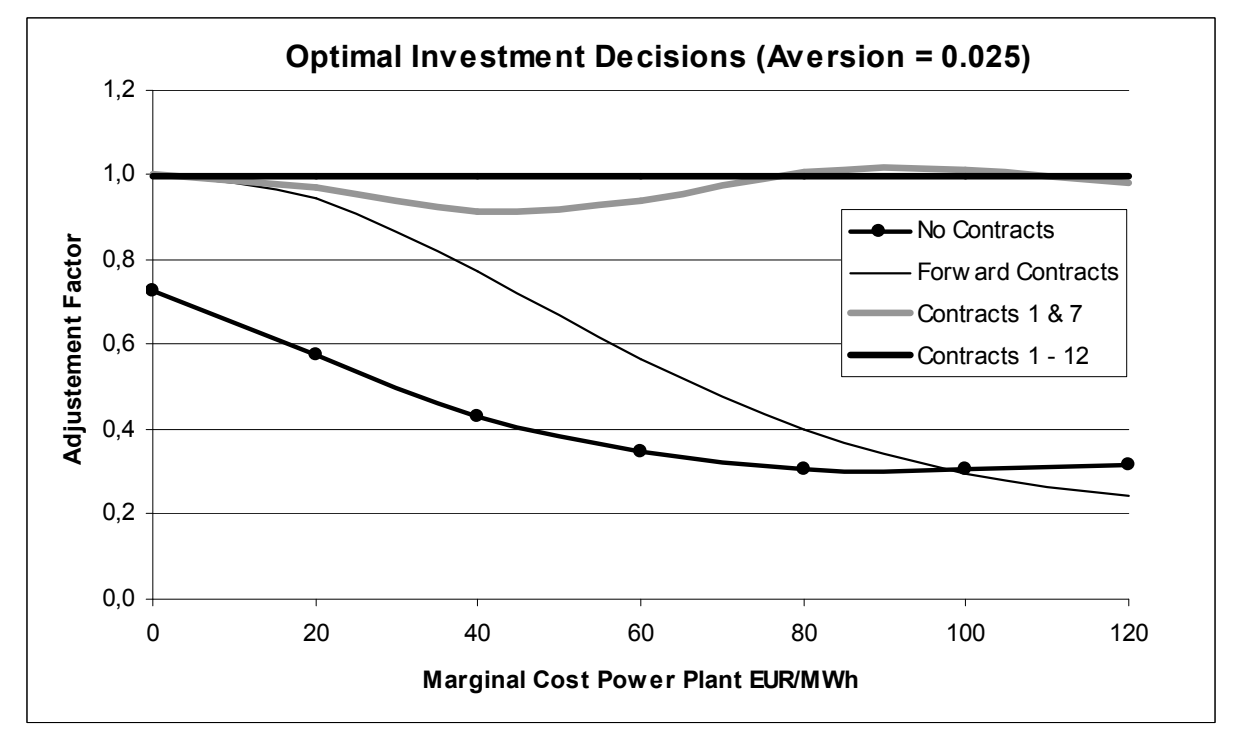

Figure 2: Optimal investment decisions.

The effect of increasing market completeness is very different for base load plants on the one hand, and peak load plants on the other hand. Once the forward contract is introduced, a firm with a base load plant $(c \approx 0)$ would be able to hedge its position completely. Adding additional derivatives to the market does not change the investment decisions for a base load power plant, as the firm already has perfect information in evaluating the value of the power plant using the forward contract. Speculation and investment decisions are decoupled: a firm wanting to invest in a base load power plant can do so without taking any market risk (i.e., it can focus on the operational aspects), while a speculator can decide to assume some base load market risk without actually having to build a power plant.

For peak load plants ( $c$ large), the results are quite different. Once the forward contract is introduced (and no options), investment in certain peak load power plants with very high marginal cost (higher than 100 EUR/MWh in Figure 2) may actually be less than if no contracts are traded. The reason for this is that it may be more profitable for the firm to speculate on the forward market (without building a power plant), than to build a power plant and use financial contracts to hedge its portfolio. Hence, financial investments 'crowd out' the investments in physical assets: investment and speculation decisions are coupled. As more and more contracts are introduced, we see that investment in peak generation increases dramatically, because there are better instruments to hedge the risk of the production output of the firm. As a result, the investment decision and the speculation decision become 
decoupled again. The figure also shows that for the technology with marginal production costs around $78 \mathrm{EUR} / \mathrm{MWh}$, adding additional contract markets on top of contract number 7 does not change the results. Contract 7 has a strike price of approximately $78 \mathrm{EUR} / \mathrm{MWh}$, hence the investment valuation of the firm is perfect, regardless of any additional contracts being added.

Note that in certain cases the adjustment factor $\kappa$ might be larger than one, which implies that a firm might invest more when markets are incomplete than when markets are complete. This may happen when the investment increases the risk of the existing firms in the sector. In that case it would be cheaper for the firm to buy a financial option with an equivalent strike price, than to invest in physical capacity. Such a financial option would be available at a 'depressed' price, i.e. a price below its expected value, because it reduces risk of the existing firms. Put otherwise, the availability of an extra derivative market creates additional investments opportunities for the firm. If those opportunities are very profitable, then the firm uses its capital to speculate on the derivatives market, instead of investing it in new power plants. In other words, the opportunity cost of risk-bearing capital has increased with the availability of new investment opportunities. Similar to what we have observed for peak load plants when a forward contract is introduced, we see that financial investments 'crowd-out' physical investments. ${ }^{18}$

The previous discussion assumes that the investor actually has access to all contracts traded in the market. It is interesting to consider the investment incentives of a completely new entrant who trades neither physically nor financially before investing. Suppose for instance that forward contracts (but no options) are traded in the market. For power plants with marginal cost smaller than $100 \mathrm{EUR} / \mathrm{MWh}$, an investor who has no market access would underinvest, as can be seen from Figure 2. Indeed, given that the investor does not utilize the hedging possibilities offered by the market (i.e., the forward contract), his risk aversion reduces his investment, especially for plants that can be hedged very well using the available contracts (in particular: base load plants). The investor therefore foregoes potential profits by not having market access. The opposite happens for power plants with marginal cost

\footnotetext{
${ }^{18}$ Crowding out of physical investments can only happen in incomplete markets. Once a power plant is fully hedged, crowding-out no longer occurs. The investment in the power plant becomes risk-free, and will therefore no longer put a burden on the risk-bearing capacities of the firm.
} 
larger than 100 EUR/MWh: investing in the power plant is in fact a less profitable use of the investor's 'risk budget' (i.e., his capital) than investing in forward contracts. An investor without market access would overinvest in power plants, and forego the potential profits of speculation with forwards.

\section{Information content of derivatives prices: risk-free probabilities}

In the previous section, we studied the effect of financial contracts on the investment decisions of a firm as a function of the technology parameter $c$. In this section we look at the information content contained in the prices of financial products, and derive optimal investment decisions based upon a typical financial approach using risk-free probabilities. This approach uses the price data from the financial market to estimate the risk-free probabilities and then computes the market value of an asset as its expected value under the risk-free probability measure. The investment decision is made by comparing the market value of the asset with the investment costs of the asset. In a sense, this approach measures the 'information content' of the derivatives prices. The approach assumes that the market is sufficiently complete to create a portfolio of contracts which replicates the pay-off of the physical asset. In this section we will test at which point markets are sufficiently complete to use the riskfree probabilities approach. We will compare the investment decisions based on the risk-free probabilities approach with the optimal decisions we found in the previous section.

The market equilibria in Table 1 can be represented by means of a risk-free probability distribution $\theta$, different from the true distribution. Under the risk-free probability distribution, the contracts' prices are equal to their expected values:

$$
\mathrm{E}_{\theta}(\vec{T})=\vec{F}
$$

and the generator and the retailer act as risk neutral agents who optimize expected profit:

$$
j=r, g \quad U_{j}=\mathrm{E}_{\theta}\left(\Pi_{j}\right)
$$

Figure 3 shows the risk-free probabilities for different assumptions regarding the number of products being traded. ${ }^{19}$ When all financial contracts are traded, the risk-

\footnotetext{
${ }^{19}$ As the set of forward and option markets is incomplete, the risk-free probability distribution is not uniquely determined by the observable market prices. We estimate the risk-free probabilities using a
} 
free probability distribution assumes that extreme events, especially low prices, are more likely to occur than they do in reality. When only forward contracts are traded, however, the risk-free probabilities calculated on the basis of forward prices, give extreme events a too small probability. Adding just one extra financial market brings the distribution relatively close to the situation in which all 12 financial products are traded, and greatly improves the information that firms obtain.

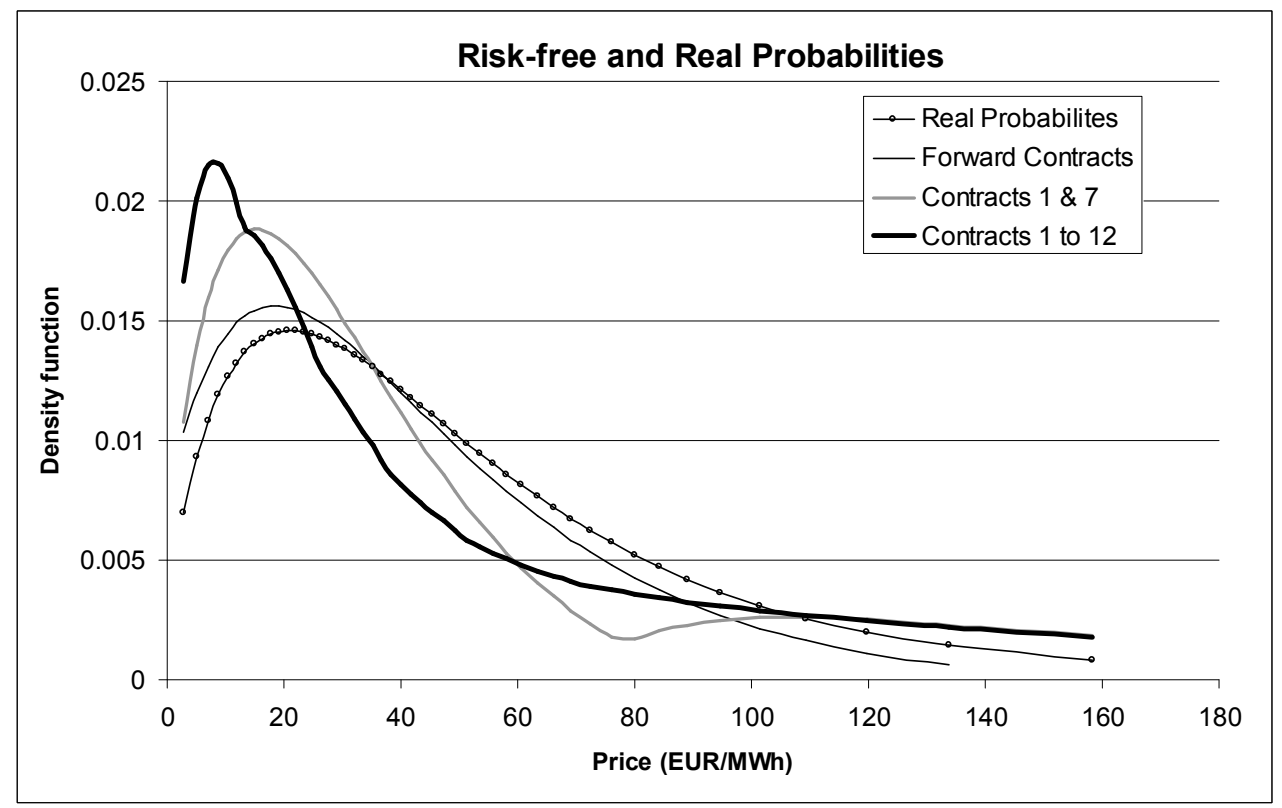

Figure 3: Risk-free probabilities without speculators.

In the risk-free probabilities approach, firms invest in a power plant when the expected net present value, calculated using the risk-free probabilities, is larger than the fixed investment cost. Hence a firm invests if

$$
F<N P V_{\theta}(c)=\mathrm{E}_{\theta}\{\max (p-c, 0)\}
$$

slightly modified version of the approach suggested by Stutzer (1996). The approach of Stutzer (1996) is essentially a Bayesian framework in which the risk-free probabilities are estimated using the historical real probabilities as a prior (thereby maximizing the observed entropy). In our model setting, we use the available real probabilities instead of 'historical' real probabilities. Furthermore, we replaced Stutzer's maximum-entropy objective function with the minimum-distance objective function suggested by Rubinstein (1994), in order to reduce computational complexity. Jackwerth and Rubinstein (1996) had already pointed out the computational challenges of the maximum-entropy objective function and had observed that results with a minimum-distance objective function are very similar. 
As in section 6 we compare these critical values with $\overline{N P V}_{\theta}(c)=\bar{F}^{c r}(c)$, the net present value of a power plant with marginal cost $c$ calculated using the risk-free probabilities inferred when all contracts are traded. Figure 4 shows - for different types of generation plants - the ratio of both numbers. We use the index $R F$ (riskfree probabilities) to distinguish the result from the previous section:

$$
\kappa^{R F}=\frac{N P V_{\theta}(c)}{\overline{N P V} \theta(c)}
$$

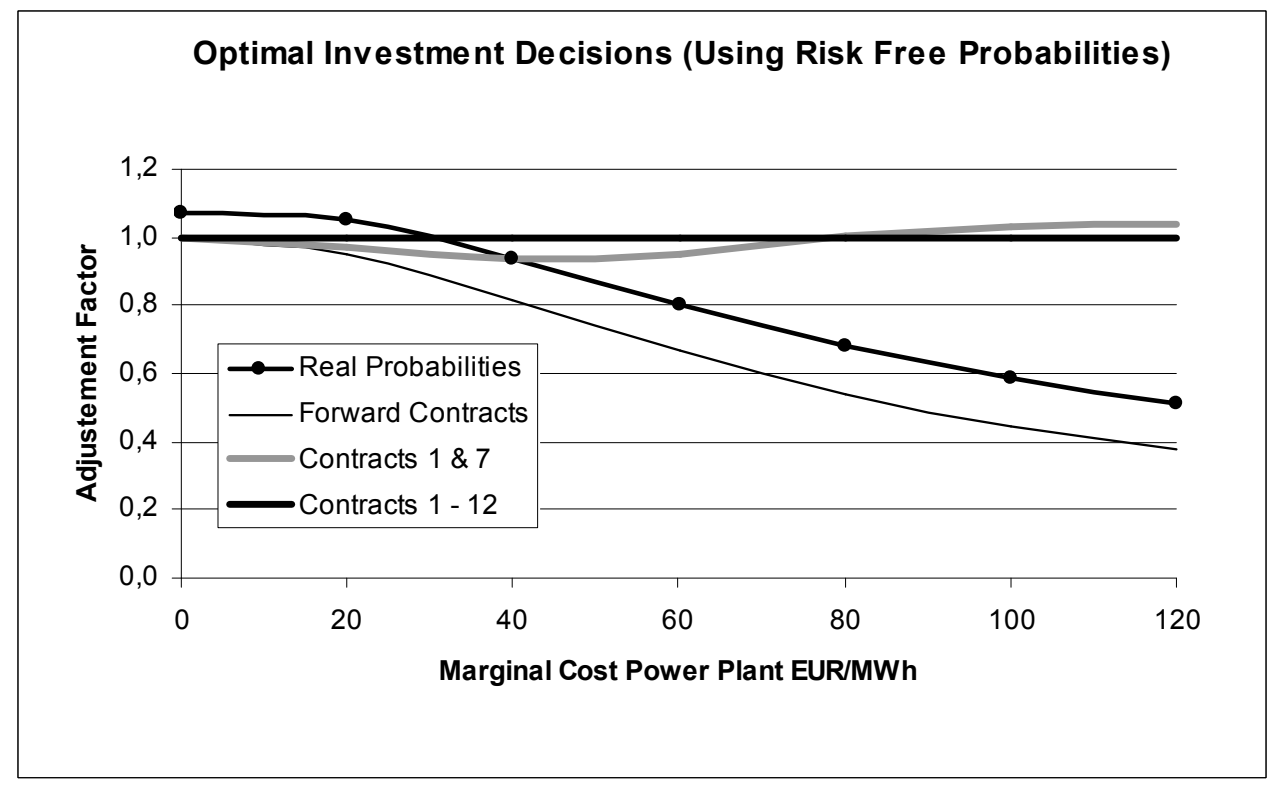

Figure 4: Investment decisions using risk-free probabilities.

The results are similar to those obtained in section 6 . In order to see whether the information content of the prices is sufficient, we compare the decisions of the riskfree probabilities approach with the optimal decisions described in section 6. Figure 5 shows the difference between the two decision rules:

$$
\Delta \kappa=\frac{N P V_{\theta}(c)-F^{c r}(c)}{\overline{N P V}_{\theta}(c)}=\kappa^{\mathrm{RF}}-\kappa
$$




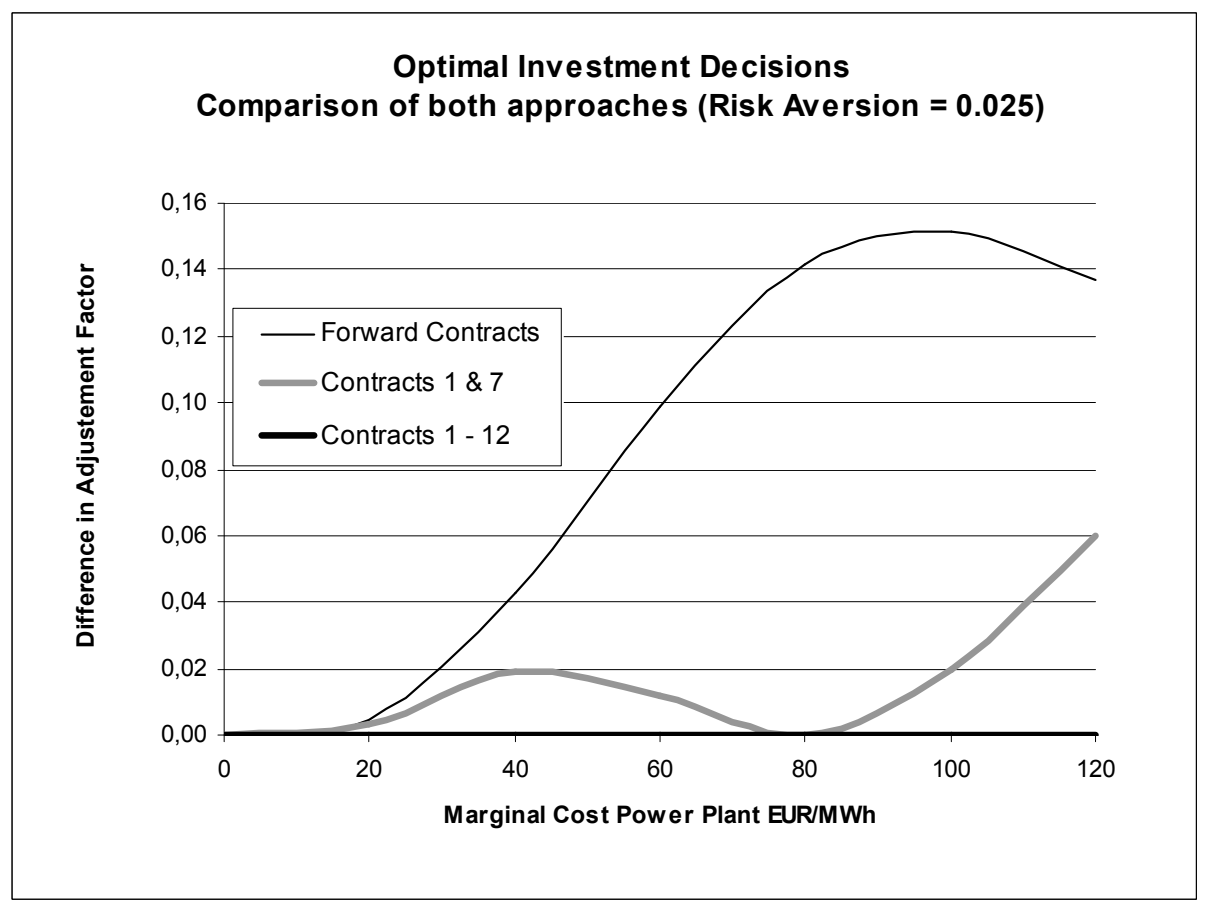

Figure 5: Difference of the risk-free probabilities approach and the optimal investments

Figure 5 shows that if the marginal cost of the power plant is equal to the strike price of one of the contracts traded in the market, the two approaches produce identical results. In general, the error in using risk-free probabilities is smaller when the contracts traded correspond better to the risk profile of the power plant being built. Hence, the decisions to build base load power plants are always efficient when there is a forward contract. Similarly, if the market trades an option with a strike price very close to the marginal cost of a certain peak power plant, the investment decision for that power plant based on risk-free probabilities is optimal.

On the other hand, the risk-free probabilities approach leads to overinvestment in power plants for which no close financial substitutes are traded in the market. For example, if only forward contracts are available, the investment decision for a peak power plant can be seriously distorted. In our model setting firms may make an error of more than $15 \%$ when evaluating this decision. The addition of one option contract eliminates this error for almost all types of power plants. In general, as more contracts are being traded, the risk-free probabilities approach leads to decisions that are closer to the optimal decisions. When markets are complete, the two approaches yield identical results. 


\section{Conclusions}

The contribution of this paper is that it studies the effects of market completeness on welfare and on investment incentives, in an equilibrium model of the spot and derivative markets in the electricity sector.

With respect to welfare, the numerical results of the model (calibrated with German market data) show that welfare is enhanced when options are offered in the market in addition to forward contracts. However, it turns out that most of the welfare benefits are achieved with one to three options. The need for options is especially relevant if firms have a strong aversion of liquidity problems (bankruptcy risk): with a CRRA utility function, aggregate welfare is infinitely low when no options are present. Allowing speculators to actively trade in the market, eliminates the risk premium, and increases aggregate welfare. The beneficial effect of speculators increases as more contracts are traded.

With respect to investment incentives, financial contracts are important for (1) hedging the risk of the entrant, and (2) signaling to entrants how they could reduce the overall sector risk. When no financial contracts are traded, risk averse firms will tend to invest less than if a complete set of financial contracts is present. When forward contracts are traded, investment in base load power plants increases (investment and speculation are decoupled), but investment in certain peak load plants declines because it is more attractive to speculate with forward contracts instead (investment and speculation are coupled, and financial investments may 'crowd-out' physical investments). When options are added to the market, investment in peak power plants increases again dramatically (investment and speculation become more and more decoupled).

We test at which point markets are sufficiently complete so that a firm can base its investment decisions on a financial approach using risk-free probabilities, in other words, at which point the information content contained in the prices is sufficient for investment purposes. We show that as long as a perfectly matching contract is traded, the risk-free probabilities approach leads to optimal investment decisions. However, for power plants for which no close financial proxy is available, the riskfree probabilities approach can lead to significant overinvestment, especially for peak load power plants. As more and more options are added to the markets, the 
investment error decreases. This shows that the quality of the information contained in market prices improves as markets become more complete.

\section{References}

Aid, R, Porchet, A., and N. Touzi. 2006, Vertical integration and risk management in competitive markets of non-storable goods. 29 September 2006. Centre de Mathématiques Appliquées: Ecole Polytechnique.

Allaz, B. and J.L. Vila. 1993, Cournot competition, forward markets and efficiency, Journal of Economic Theory 59, 1-16.

Allen, F. and D. Gale. 1994, Financial Innovation and Risk Sharing. 1994. Cambridge, MIT press.

BAFA. 2006, http://www.bafa.de/1/de/aufgaben/energie/. Retrieved 21.08.06.

Baldursson, F. M. and N.-H. von der Fehr. 2007, Vertical Integration and Long-Term Contracts in Risky Markets. January 31, 2007. Working paper.

Bessembinder, H. and M.L. Lemmon. 2002, Equilibrium Pricing and Optimal Hedging in Electricity Forward Markets. Journal of Finance 57, 1347-1382.

Borenstein, S., 2007, Customer risk from real-time retail electricity pricing: Bill volatility and hedgability. Energy Journal 28(2), 111-129.

Boyle, P. and T. Wang. 2001, Pricing of new securities in an incomplete market: The catch 22 of noarbitrage pricing, Mathematical finance 11, 267-284.

Carr, P., H. Geman, and D.B. Madan. 2001, Pricing and hedging in incomplete markets, Journal of Financial Economics 62, 131-167.

Cass, D. and A. Citanna. 1998, Pareto improving financial innovation in incomplete markets, Economic Theory 11, 467-494.

Centrica. 1997-2001, Press releases: "Extraordinary General Meeting: British Gas Shareholders Approve Demerger" (12/2/1997), "British Gas signs up its first electricity customers" (1/12/1997), "Centrica delivers generation for growing electricity customer base" (29/5/2001), "Centrica acquires further electricity generation" (24/8/2001). Centrica Media Relations, Centrica corporate website (http://www.centrica.co.uk).

Duffie, D. and R. Rahi. 1995, Financial market innovation and security design - an introduction, Journal of Economic Theory 65, 1-42. 
Duffie, D. and W. Shafer. 1985, Equilibrium in incomplete markets I: A basic model of generic existence, Journal of Mathematical Economics 65, 1-42.

Duffie, D. and W. Shafer. 1986, Equilibrium in incomplete markets II: Generic existence in stochastic economies, Journal of Mathematical Economics 15, 199-216.

Elul, R. 1995, Welfare effects of financial innovation in incomplete markets economies with several consumption goods, Journal of Economic Theory 65, 43-78.

Elul, R. 1999, Welfare-improving financial innovation with a single good, Economic Theory 13, 113131.

Eydeland, A. and H. Geman. 1998, Pricing power derivatives, Risk Magazine October 1998, 71-73.

Green, R. 2003, Electricity contracts and retail competition. December 2003. University of Hull.

Green, R. 2007, Carbon tax or carbon permits: The impact on generators' risks. January 15-16, 2007. Conference on "The Economics of Energy Markets", Toulouse.

Hart, O. 1975, On the optimality of equilibrium when the market structure is incomplete, Journal of Economic Theory 11, 418-835.

Hoster. F., 1996, Auswirkungen des europäischen Binnenmarktes für Energie auf die deutsche Elektrizitätswirtschaft. Munich: Oldenbourg.

Jackwerth, J. and M. Rubinstein. 1996, Recovering probability distributions from option prices, Journal of Finance 51-5, 1611-1632.

Milne, F. and H.M. Shefrin. 1987, Information and securities: A note on Pareto dominance and second best, Journal of Economic Theory 43, 314-328.

Oh, G. 1996, Some results in the CAPM with nontraded endowments, Management Science 42, 286293.

Oum, Y., Oren, S., and Deng, S. 2007, Hedging quantity risks with standard power options in a competitive wholesale electricity market. Naval Research Logistics 53(7), .601-726.

Palsson, A.-M. 1996, Does the degree of relative risk aversion vary with household characteristics? Journal of Economic Psychology 17, 771-787.

Rubinstein, M. 1994, Implied binomial trees, Journal of Finance 49, 771-818.

Schröter, J. 2004, Auswirkungen des europäischen Emissionshandelssystems auf den Kraftwerkseinsatz in Deutschland. diploma thesis, Berlin University of Technology, Institute of Power Engineering. 
Siddiqui, A. S. 2003, Managing electricity reliability risk through the forward narkets, Networks and Spatial Economics 3, 225-263

Staum, J. 2008, Incomplete Markets, in: J.R. Birge and V. Linetsky, eds., Handbooks in Operations Research and Management Science 15, 511-563.

Stutzer, M. 1996, A simple nonparametric approach to derivative security valuation, Journal of Finance 51, 1633-1652.

VGE. 2006, Jahrbuch der europäischen Energie- und Rohstoffwirtschaft 2006. Essen: Verlag Glückauf GmbH.

Willems, B. 2006, Virtual divestitures, will they make a difference? Cournot competition, option markets and efficiency. May 2006. Berkeley. CSEM Working Papers.

Willen, P. 2005, New financial markets: Who gains and who loses, Economic Theory 26, 141-166.

\section{Appendix A: Construction of the German marginal production cost curve}

The marginal production cost curve $C^{\prime}(Q)$ (see equations (1) and (2)) is calibrated on the actual German marginal production cost curve, as shown in Figure 6. The parameters chosen in order to obtain a reasonable fit, are $c=4, a=1.85210^{-4}$.

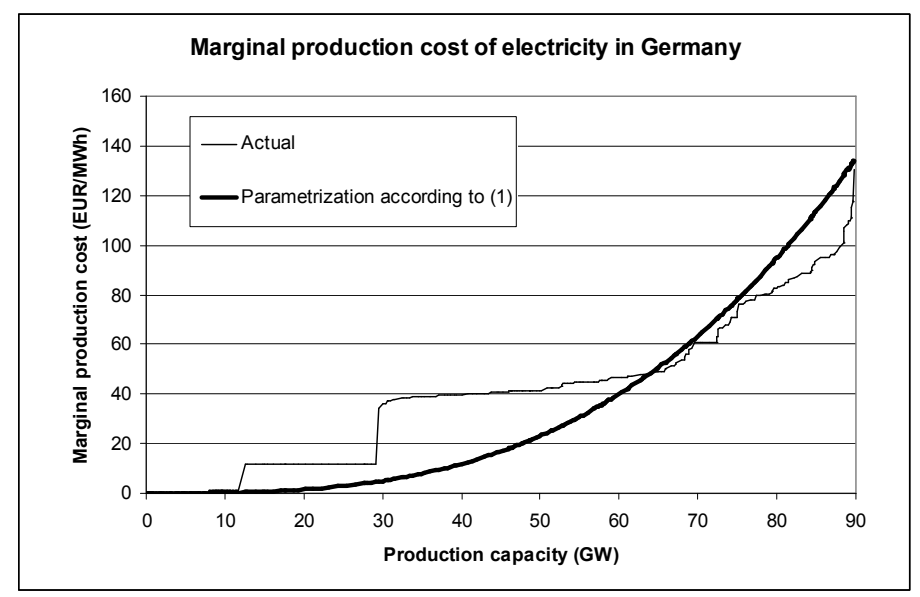

Figure 6: Industry marginal cost

Generation capacities and ownership are obtained from VGE (2006). More than 300 power plants are considered, totaling $100 \mathrm{GW}$ of generation. Wind, biomass and solar capacities are not considered within the firm's generation portfolios. Plant capacities are decreased by seasonal availability factors following Hoster (1996). Using a type-specific algorithm based on Schröter (2004) with construction year as 
proxy, we calculate a plant-specific efficiency to derive marginal costs. Fuel prices are taken from BAFA (2006) and resemble average monthly cross-border prices for gas, oil and coal. We include the price of $\mathrm{CO}_{2}$-emission allowances in the cost estimate based on fuel type and plant efficiency. Allowance prices are taken from the EEX.

\section{Appendix B: Numerical model}

The equilibrium model is solved as a Mixed Complementarity Problem (MCP) in GAMS. By writing the problem as a MCP, we can simultaneously determine the equilibrium prices and quantities of derivatives.

\section{Spot market}

The following equations are considered for the spot market:

$$
\begin{array}{ll}
C_{s}=F+\frac{a}{c} D_{s}^{c} & P_{s}=a Q_{g s}{ }^{c-1} \\
\pi_{g s}=P_{s} \cdot D_{s}-C_{s} & \pi_{r s}=\left(R-P_{s}\right) D_{s}
\end{array}
$$

with $s$ the state of the world and the indices $g$ and $r$ indicating generator and retailers.

\section{Call option}

The call option $i$ pays $T_{i s}$ in state $s$, with $T_{i s}=\max \left(P_{s}-S_{i}, 0\right)$.

Equilibrium in the derivatives markets

$$
\begin{array}{ll}
\Pi_{g s}=\pi_{g s}+\sum_{i=1}^{I} k_{g i} \cdot\left(T_{i s}-F_{i}\right) & \Pi_{r s}=\pi_{r s}+\sum_{i=1}^{I} k_{r i} \cdot\left(T_{i s}-F_{i}\right) \\
E \Pi_{g}=\sum_{s=1}^{S} \rho_{s} \Pi_{g s} & E \Pi_{r}=\sum_{s=1}^{S} \rho_{s} \Pi_{r s} \\
\sum_{s=1}^{S}\left(1-A\left(\Pi_{g s}-E \Pi_{g}\right)\right) \rho_{s} T_{i s}=F_{i} & \sum_{s=1}^{S}\left(1-A\left(\Pi_{r s}-E \Pi_{r}\right)\right) \rho_{s} T_{i s}=F_{i} \\
k_{r i}+k_{g i}=0 &
\end{array}
$$




\section{Risk-free probabilities}

The risk-free probabilities are chosen such that the price of each financial instrument equals its expected value under the risk-free probability measure, and that the difference between the risk-free probabilities and the true probabilities is minimized:

$$
\begin{aligned}
& \sum_{s=1}^{S} \theta_{s} T_{i s}=F_{i} \perp \mu_{i} \\
& \sum_{s=1}^{S} \theta_{s}=1 \perp \omega \\
& 2\left(\theta_{s}-\rho_{s}\right)-\omega-\sum_{i=1}^{I} \mu_{i} T_{i s}=0 \perp \theta_{s} \geq 0
\end{aligned}
$$

